\title{
Low expression of ANT1 confers oncogenic properties to rhabdomyosarcoma tumor cells by modulating metabolism and death pathways
}

\author{
J. Viall', P. Huchedé ${ }^{1}$, S. Fagault ${ }^{1}$, F. Basset' ${ }^{1}$, M. Rossi ${ }^{2}$, J. Geoffray ${ }^{1}$, H. Soldati ${ }^{3}$, J. Bisaccia ${ }^{1}$, M. H. Elsensohn ${ }^{4}$, M. Creveaux ${ }^{1}$, \\ D. Neves ${ }^{5}$, J. Y. Blay (1) ${ }^{1}$, F. Fauvelle ${ }^{6}$, F. Bouquet ${ }^{7}$, N. Streichenberger ${ }^{8,9}$, N. Corradini', C. Bergeron', D. Maucort-Boulch ${ }^{4}$, \\ P. Castets ${ }^{3}$, M. Carré $\mathbb{D}^{2}$, K. Weber ${ }^{1}$ and M. Castets $^{1}$
}

\begin{abstract}
Rhabdomyosarcoma (RMS) is the most frequent form of pediatric soft-tissue sarcoma. It is divided into two main subtypes: ERMS (embryonal) and ARMS (alveolar). Current treatments are based on chemotherapy, surgery, and radiotherapy. The 5-year survival rate has plateaued at $70 \%$ since 2000 , despite several clinical trials. RMS cells are thought to derive from the muscle lineage. During development, myogenesis includes the expansion of muscle precursors, the elimination of those in excess by cell death and the differentiation of the remaining ones into myofibers. The notion that these processes may be hijacked by tumor cells to sustain their oncogenic transformation has emerged, with RMS being considered as the dark side of myogenesis. Thus, dissecting myogenic developmental programs could improve our understanding of RMS molecular etiology. We focused herein on ANT1, which is involved in myogenesis and is responsible for genetic disorders associated with muscle degeneration. ANT1 is a mitochondrial protein, which has a dual functionality, as it is involved both in metabolism via the regulation of ATP/ADP release from mitochondria and in regulated cell death as part of the mitochondrial permeability transition pore. Bioinformatics analyses of transcriptomic datasets revealed that ANT1 is expressed at low levels in RMS. Using the CRISPR-Cas9 technology, we showed that reduced ANT1 expression confers selective advantages to RMS cells in terms of proliferation and resistance to stress-induced death. These effects arise notably from an abnormal metabolic switch induced by ANT1 downregulation. Restoration of ANT1 expression using a Tet-On system is sufficient to prime tumor cells to death and to increase their sensitivity to chemotherapy. Based on our results, modulation of ANT1 expression and/or activity appears as an appealing therapeutic approach in RMS management.
\end{abstract}

\section{Introduction}

Childhood cancers may be considered as aberrations of pre- and postnatal ontogeny, resulting from dysregulated

\footnotetext{
Correspondence: M Castets (marie.castets@lyon.unicancer.fr)

${ }^{1}$ Cell death and Childhood Cancers Laboratory-Equipe labellisée LabEx DEV2CAN, Centre de Recherche en Cancérologie de Lyon, INSERM U1052CNRS UMR5286, Université de Lyon, Centre Léon Bérard, 69008 Lyon, France ${ }^{2}$ Aix-Marseille Université, Inserm UMR_S 911, Centre de Recherche en Oncologie biologique et Oncopharmacologie, Faculté de pharmacie, Marseille, France

Full list of author information is available at the end of the article

These authors contributed equally: J. Vial, P. Huchedé

These authors jointly supervised this work: K. Weber, M. Castets

Edited by Ivano Amelio
}

developmental processes ${ }^{1,2}$. Development is characterized by rapid proliferative expansion of cells, their migration along appropriate routes towards organs, tissue refinement by elimination of excessive cells, and the terminal differentiation of survivors into normal cell types. In particular, during development, cells in excess are secondarily pruned through switches in developmental programs governing survival; the regulation of cell suicide pathways is then crucial. It has notably been postulated that during early embryogenesis, a pool of myoblasts is generated in somites during skeletal muscle development ${ }^{3}$. A fraction of these cells undergoes differentiation,

\section{(c) The Author(s) 2020}

(c) (i) Open Access This article is licensed under a Creative Commons Attribution 4.0 International License, which permits use, sharing, adaptation, distribution and reproduction cc) in any medium or format, as long as you give appropriate credit to the original author(s) and the source, provide a link to the Creative Commons license, and indicate if changes were made. The images or other third party material in this article are included in the article's Creative Commons license, unless indicated otherwise in a credit line to the material. If material is not included in the article's Creative Commons license and your intended use is not permitted by statutory regulation or exceeds the permitted use, you will need to obtain permission directly from the copyright holder. To view a copy of this license, visit http://creativecommons.org/licenses/by/4.0/. 
another subset exits cell cycle to constitute a niche of resting stem cells, while the remaining are likely eliminated through different regulated forms of cell death ${ }^{3}$. During development, some supernumerary cells resist these death signals as a potential first pathological step towards cancer ${ }^{1}$. This tumor resistance to cell death also plays a key role in constitutive or acquired resistance to treatments ${ }^{4}$.

Rhabdomyosarcoma (RMS) is the most frequent form of pediatric soft-tissue sarcoma, accounting for $5 \%$ of solid pediatric tumors, with a 5 -year survival rate that caps at $60-70 \%{ }^{5,6}$. Molecular bases of RMS remain unclear, notably in the sizeable fraction of translocation negative tumors. Regarding cell death resistance, the prognosis has been correlated with the expression of Bcl family members in patients and resistance to apoptosis linked to failure of conventional therapies in RMS cell lines. However, robust characterization of cell death pathways altered in RMS is still lacking ${ }^{5,7}$. RMS are thought to arise from malignant transformation of muscle precursors ${ }^{6}$. Embryonal RMS (ERMS), so-called because they resemble embryonic muscle, present various degrees of myogenic differentiation, ranging from small round cells to larger oblong ones, sometimes having a strap-like appearance for the most differentiated ones, occasionally with cross striations and multinucleation ${ }^{6}$. Aside from these morphological observations supporting the myoblast-like nature of tumor cells, RMS expression signatures are also characterized by widespread expression of embryonic muscle-specific markers such as myogenin, desmin, or MyoD. Moreover, the notion that the molecular pathogenesis of RMS shares similarities with processes involved in myogenesis or mechanisms that have gone awry in muscular dystrophies has begun to emerge ${ }^{8-10}$. Besides gold standard effectors of death pathways, we hence hypothesized that genes involved in specific cell survival/ death imbalance during myogenesis or in the etiology of muscular dystrophies may also play a role in RMS tumorigenesis.

Based on exhaustive bioinformatics-driven bibliographic data mining, we identified adenine nucleotide translocator 1 (ANT1) as a potent player in RMS. ANT1 is the heart- and muscle-specific isoform of the ANT mitochondrial inner membrane protein family. ANT1 plays a role in myoblast differentiation ${ }^{11}$ and is associated with mitochondrial myopathy and cardiomyopathy ${ }^{12-14}$. ANT1 regulates ATP/ADP exchange across the mitochondrial inner membrane. Indeed, it exports ATP produced by OXPHOS metabolism to the cytoplasm to power cellular reactions and simultaneously imports ADP to restore intra-mitochondrial stock. ANT1 was also initially described as a key component of the socalled mitochondrial permeability transition pore (mPTP), a solute channel assembled at the junction between the inner and the outer mitochondrial membrane whose opening triggers mitochondrial permeability transition $(\mathrm{MPT})^{15-17}$. Although this view was challenged ${ }^{18}$, pharmacological and genetic inactivation of ANT family members have strengthened the idea that ANT proteins are indeed involved, at least to some extent, in $\mathrm{mPTP}$ formation/regulation ${ }^{19-22}$. $\mathrm{mPTP}$ opening drives osmotic influx of water into mitochondrial matrix, resulting in the collapse of these organelles. This ultimately leads to execution of regulated cell death, whether it be MPT-driven necrosis or apoptosis, the latest being induced by the release of the cytochrome c from the mitochondrial intermembrane space and the subsequent activation of executioner caspases ${ }^{19,21-23}$. ANT1 is hence considered to be at the crossroad of several cell death and metabolic signaling pathways. Here, we show that ANT1 encoding gene, SLC25A4 (further referred to as ANT1), is expressed at low levels in RMS tumors. Using the inducible CRISPR-Cas9 strategy, we establish that downregulation of ANT1 expression in RMS cells increases both their proliferation and their resistance to stress-induced cell death. Importantly, restoring ANT1 expression is sufficient to counteract resistance to cell death and to increase sensitivity of tumor cells to chemotherapy. Hence, we unveil a potent role for ANT1 as a new tumor suppressor in RMS.

\section{Results \\ Low levels of ANT1 expression in RMS favor tumor cell proliferation}

Changes in ANT1 expression have been reported in several disorders and are notably associated with muscular defects ${ }^{24-27}$. However, its expression profile in cancers has so far barely been studied, especially in RMS. To analyze the expression levels of ANT1 in RMS, we first performed a bioinformatics analysis of the publicly available GSE28511 dataset, dedicated to the comparison of normal skeletal muscle tissue $(n=6)$ versus RMS $(n=$ 8 ERMS and $n=10$ ARMS). We observed that the expression of ANT1 is significantly lower (24-fold reduction) in RMS than in non-tumoral skeletal muscle (threefold reduction at the most for the electron transport chain protein COX7C or the mitochondrial hexokinase HK1) (Fig. 1a). As previously reported in other cancers, the expression of the ANT2 encoding gene, SLC25A5, increased threefold in tumors ${ }^{28,29}$. We confirmed this result by RT-qPCR, by showing that the level of ANT1 expression was higher in adult, fetal, and dystrophic muscles than in 67 pediatric RMS samples (Fig. 1b). Using the E-TABM-1202 dataset, we observed that high ANT1 expression levels tend to be positively associated with a better outcome in fusion-negative RMS, although this observation needs to be confirmed on a larger cohort (Fig. S1a). 


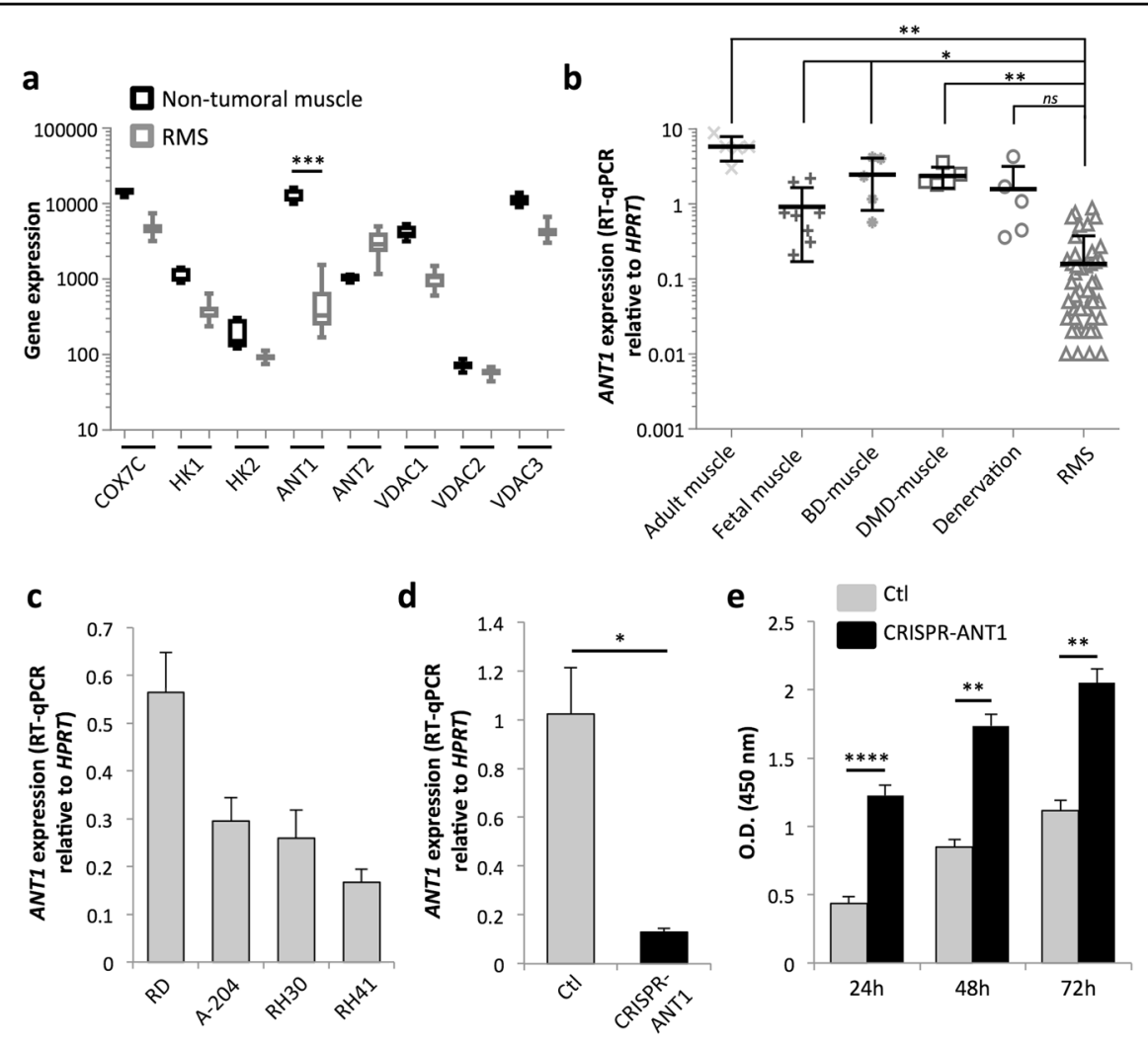

Fig. 1 Low ANT1 expression in RMS favors tumor cell proliferation. a Bioinformatics analysis of the expression of the ANT1 gene (SLC25A4) and of some of its partners in a cohort of non-tumoral muscle $(n=6)$, ERMS $(n=8)$, and ARMS $(n=10)$ from the GSE28511 transcriptomic dataset.

${ }^{* * *} p<0.001$; two-sided independent samples T-test. b Quantification of ANT1 gene (SLC25A4) expression by RT-qPCR, relative to the housekeeping gene HPRT in RMS biopsies $(n=67)$, normal adult muscle $(n=5)$, fetal muscle $(n=9)$, and in biopsies from patients with muscle weakness (BD Becker dystrophy, DMD Duchenne muscular dystrophy, $n=5$ each). ${ }^{*} p<0.05,{ }^{* *} p<0.01$, ns not significant; two-sided independent samples $T$-test.

c Quantification of ANT1 expression by RT-qPCR, relative to the housekeeping gene HPRT in ERMS cell lines (RD and A-204), and ARMS cell lines (RH30 and RH41). Results are presented as means \pm s.d.; $n=3$. $\mathbf{d}$ Efficiency of ANT1 silencing by CRISPR-Cas9 in RD cells, $48 \mathrm{~h}$ after doxycycline treatment. Quantification of ANT1 expression by RT-qPCR, relative to the housekeeping gene HPRT. Results are presented as means \pm s.d.; $n=3$. ${ }^{*} p<0.05$; twosided independent samples T-test. e Increase in number of metabolically active cells as measured by WST-1 assay in RD ${ }^{\text {Low }}$ cells, at different time points after silencing of ANT1 expression by doxycycline treatment. Results are presented as means \pm s.d.; $n=3 .{ }^{* *} p<0.01$, ${ }^{* * * *} p<0.0001$; two-sided independent samples T-test.

We hypothesized that low ANT1 expression may confer a selective advantage to tumor cells. Using the R2 cancer software, we observed that ANT1 expression in patients tends to be negatively correlated with the expression of $C D C 7$, which has been described as an inducer of smooth muscle cell proliferation $^{30}$, and of MKI67, suggesting that ANT1 may influence cell proliferation (Fig. S1b, c). To investigate whether ANT1 impacts cell proliferation, we screened its expression in different RMS cell lines by RTqPCR (Fig. 1c). Based on this screen, we selected the ERMS RD cell line, which displayed the highest ANT1 expression level, to assess the consequences of ANT1 knock-down in RMS cells. We set up a stable doxycyclineinducible CRISPR-Cas9 system that reduced ANT1 expression by $88 \%$ (Fig. 1d), without affecting ANT2 expression (Fig. S1d). These cells will be further referred to as $\mathrm{RD}^{\mathrm{Low}}$. Decreased ANT1 expression in these cells triggered a 2.8-, 2.1-, and 1.85-fold increase in number of viable cells, 24,48 , and 72 -h post-silencing, respectively, as measured by WST-1 assay (Fig. 1e), and a $42.5 \%$ increase in viable cell concentration in normal growth conditions (Fig. S1e), without any impact on death induction (not shown). Similar results were observed by silencing ANT1 via siRNA in immortalized myoblasts (Fig. S1f, g). Thus, RMS are associated with low ANT1 expression, which may sustain tumor cell proliferation.

Loss of ANT1 confers selective advantage to tumor cells by maintaining them in a proliferative state

As ANT1 is at the crossroad of metabolic, death, and mitogen-activated signals ${ }^{31}$, increase in cell proliferation observed in $\mathrm{RD}^{\mathrm{Low}}$ cells may have multiple origins. Since ANT1 regulates metabolism by controlling ATP/ADP exchange, we first hypothesized that ANT1 downregulation 
may trigger metabolic changes sustaining their proliferative capacity. Amino acids especially those linked to the tricarboxylic acid cycle are an alternative source of energy used during cancer cell proliferation ${ }^{32}$. Interestingly, metabolomic analyses revealed significant decrease in amino-acid content in $\mathrm{RD}^{\mathrm{Low}}$ cells, including glycine (Fig. 2a). A similar decrease in glycine content has previously been associated with increased proliferation in cancer cells ${ }^{33}$. At the same time, we detected that the levels of scyllo-Inositol, choline, and glycerophosphocholine were significantly increased in $\mathrm{RD}^{\mathrm{Low}}$ cells (Fig. 2b). This can be linked to previous results showing that myogenesis is associated to a transient increase in phospholipids metabolism during the myoblasts proliferation phase, followed by a decrease in content during the late myotubes' differentiation steps ${ }^{34}$. Of note, accumulation of these metabolites is also reminiscent of high choline metabolism, which is a hallmark of cancer cells and was shown to sustain their proliferation by providing them with the necessary membrane precursors ${ }^{35}$. To extend these findings, we examined whether ANT1 downregulation also affected the oxidative capacity of the cells, by impacting the export of ATP coupled to the electron transport chain driving OXPHOS metabolism. Using the Seahorse system, we showed that reduced ANT1 expression increases basal oxygen consumption rate (OCR, Fig. 2c), considered to be a marker of OXPHOS metabolism. It is worth noting that a similar switch to OXPHOS metabolism has been described upon activation and proliferation of myogenic precursors during regeneration ${ }^{36}$. $\mathrm{RD}^{\mathrm{Low}}$ cells were slightly less glycolytic than controls, with a decrease in basal extracellular acidification rate (ECAR) of 31\% (Fig. 2d). The spare respiratory capacity (SRC) measures the extra mitochondrial capacity available in a cell to produce energy under conditions of increased demand and is calculated by the difference between the maximal and basal OCR (Fig. 2c and "Material and methods"). SRC increased slightly when ANT1 levels lowered, indicating that those cells have a greater ability to adapt to metabolic stress. Altogether, these results indicate that lowering ANT1 expression triggers a metabolic switch in RMS cells, similar to the metabolic state of proliferating muscle precursors, which may sustain the proliferative properties of tumor cells.

To determine whether the effect of ANT1 downregulation on RMS cell proliferation involves other mechanisms, besides this metabolic switch, we next assessed the status of known pathways related to ANT1 and/or involved in myoblast proliferation. While ANT1 has been reported to modulate ERK1/2 activity, we detected no change in total and phosphorylated forms of ERK1/2 (Tyr 202/204) in RD ${ }^{\text {Low }}$ cells compared to control cells. Similar levels of total and phosphorylated (active) mTOR (Ser 2448) and S6 (Ser 235/236) indicated that
mTORC1 signaling, a well-known pathway associated with cell growth, was also unaffected in $\mathrm{RD}^{\mathrm{Low}}$ cells (Fig. 2e).

During myogenesis, activation of caspases, well-known cysteine protease executioners of apoptosis, is required at a "sub-apoptotic" level to engage myoblasts in differentiation $^{37-39}$. Since ANT1 is involved in MPT that can result in apoptosis ${ }^{40,41}$, we wondered whether modulation of its expression may affect proliferation via a caspaseassociated signaling cascade. We observed that basal caspase- 3 activity was significantly decreased in $\mathrm{RD}^{\text {Low }}$ cells (Fig. 2f). Consistently, expression of the differentiation marker $M Y O G$ and the specific skeletal muscle markers TNNT3 and MYBPC1 are significantly reduced in these cells compared to control cells (Fig. 2g). Moreover, TNNT3 and MYBPC1 tend to be correlated with ANT1 in RMS patients (R2 cancer analysis, Davicioni ETABM-1202 dataset, Fig. 2h). This suggests an association between ANT1 expression and tumor cell differentiation status, which might be mediated by caspase- 3 activity.

Altogether, these results indicate that downregulation of ANT1 expression is sufficient to maintain RMS tumor cells in an immature proliferative state most likely by affecting different cellular pathways and processes.

\section{Low levels of ANT1 favor resistance of tumor cells to death induced by stress and chemotherapy}

ANT1 exerts a pro-death function notably in conditions of oxidative stress response ${ }^{42}$, as part of the mPTP. We thus decided to study the consequences of its modulation in response to $\mathrm{H}_{2} \mathrm{O}_{2}$ treatment using our CRISPR-Cas9 system. Silencing ANT1 led to an increase in the percentage of viable $\mathrm{RD}^{\text {Low }}$ cells compared to control counterparts (Fig. 3a). This effect was accompanied by a loss of mitochondrial membrane potential $\left(\Delta \psi_{\mathrm{m}}\right)$ (Fig. $\left.3 \mathrm{~b}\right) . \mathrm{H}_{2} \mathrm{O}_{2}$ triggers death via the generation of reactive oxygen species (ROS). Interestingly, increase in cell viability in $\mathrm{RD}^{\mathrm{Low}}$ cells was also concomitant to a decrease in ROS production, as measured by monitoring CellROX ${ }^{\circledR}$ fluorescence. This suggests that detoxification of ROS was more efficient in these ANT1-silenced cells (Fig. 3c).

Next, we assessed the impact of ANT1 downregulation on cell sensitivity to chemotherapy. We exposed $\mathrm{RD}^{\mathrm{Low}}$ cells and controls to increasing concentrations of chemotherapies that are used in the therapeutic management of RMS, such as Paclitaxel and Vincristine, and evaluated their impact on cell viability. As shown on Fig. 3d, ANT1 silencing reduced the sensitivity of RMS cells to Paclitaxel. Similar results were obtained with Vincristine (Fig. S1h). Hence, these results indicate that, aside from promoting cell proliferation, reduction in ANT1 expression is also sufficient to increase the resistance of RMS tumor cells to death, thereby conferring a second selective advantage to these cells. 

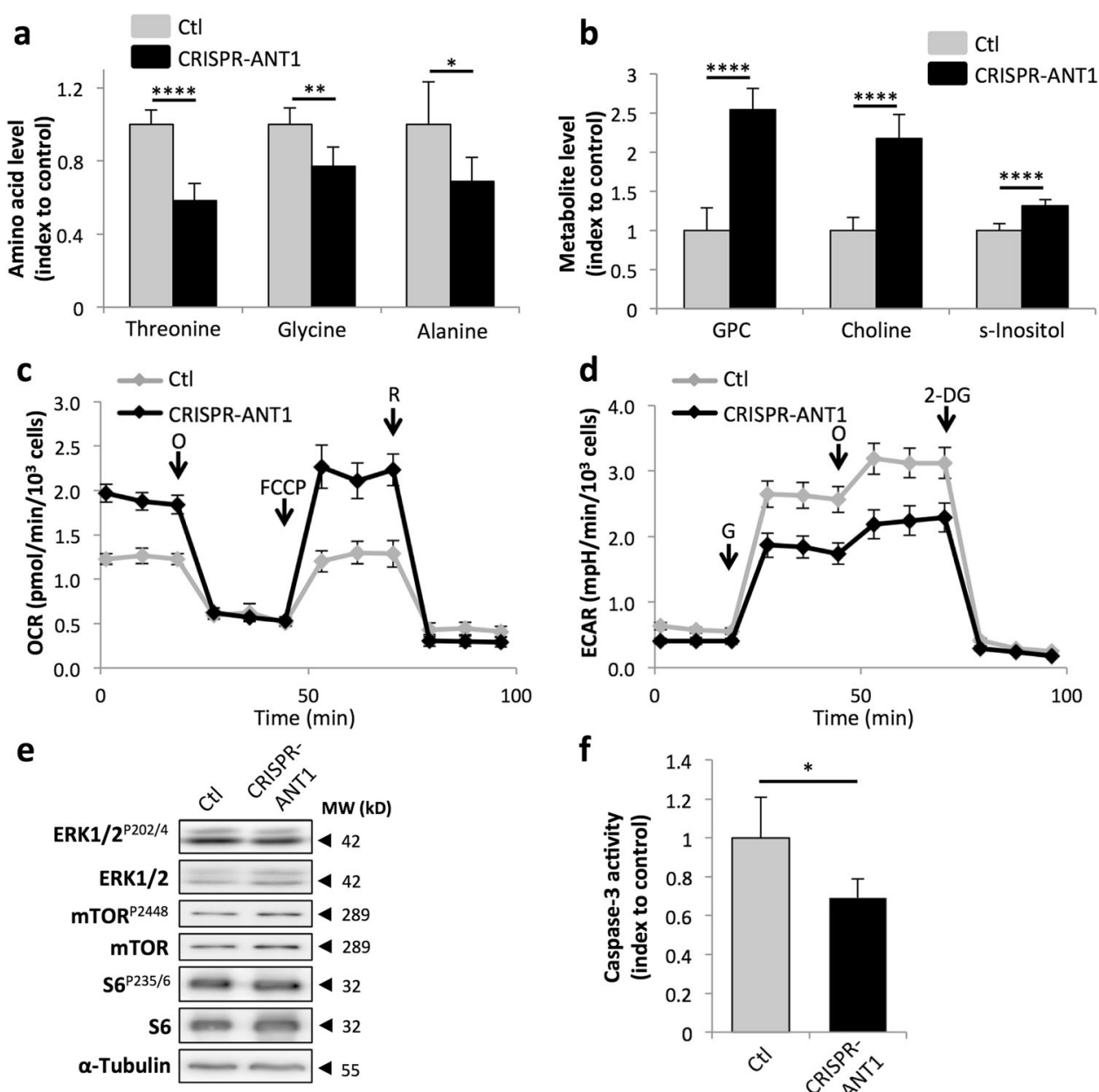

f
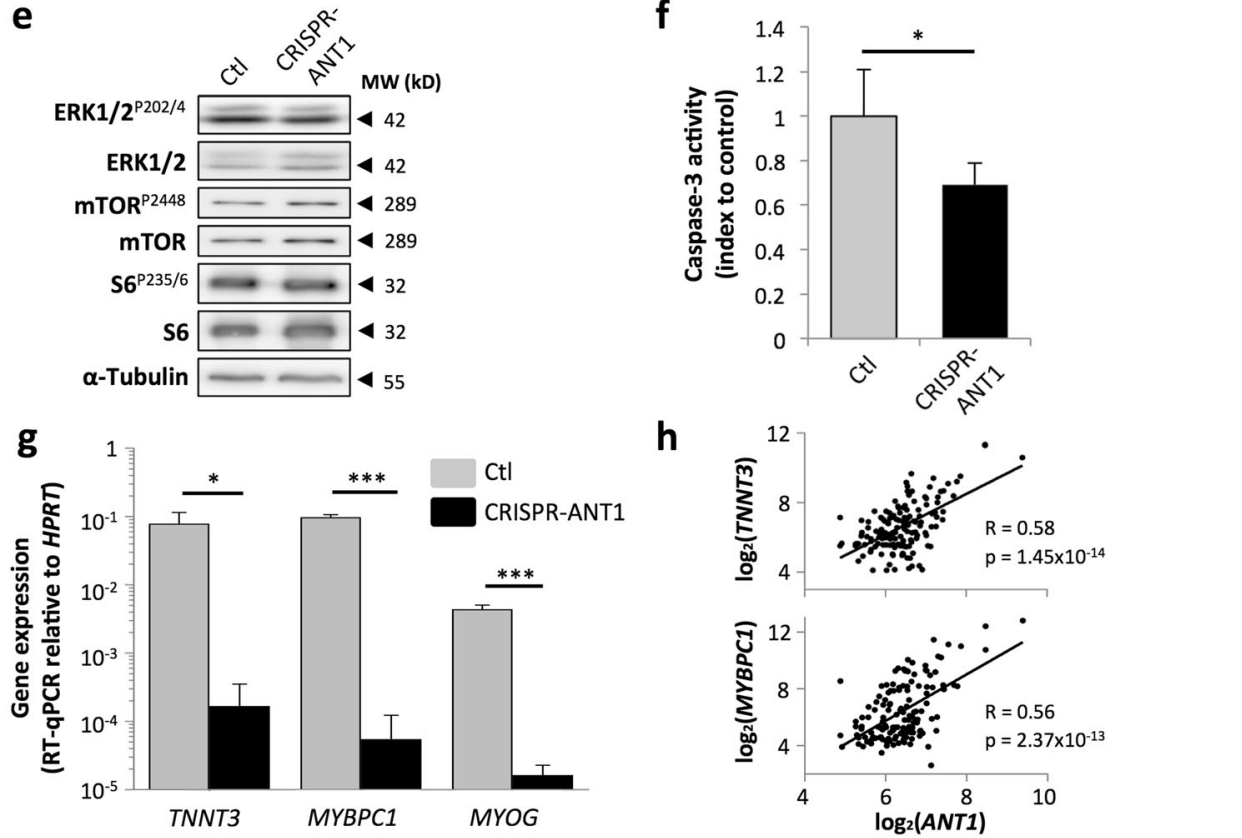

h
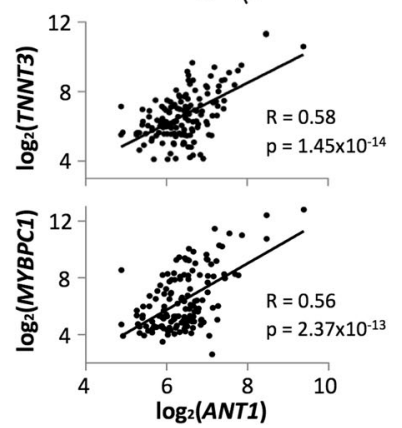

Fig. 2 Loss of ANT1 confers selective advantage to tumor cells by maintaining them in a proliferative state. a Changes in amino acid abundance in $\mathrm{RD}^{\mathrm{Low}}$ cells as compared to control cells. Results are presented as means \pm s.d. of the ratio between metabolites abundance in $\mathrm{RD}^{\mathrm{Low}}$ cells compared to control cells; $n=5 .{ }^{*} p<0.05,{ }^{* *} p<0.01$, ${ }^{* * *} p<0.0001$; two-sided independent samples $T$-test. $\mathbf{b}$ Changes in choline derivatives and inositol metabolite abundance in RD ${ }^{\text {Low }}$ cells compared to control cells. GPC glycerophosphocholine, s-Inositol scyllo-Inositol. Results are presented as means \pm s.d. of the ratio between metabolite abundance in $\mathrm{RD}^{\text {Low }}$ cells compared to control cells; $n=5$. ${ }^{* * * *} p<0.0001$; two-sided independent samples T-test. c Oxygen consumption rate (OCR) measured by Seahorse in RD ${ }^{\text {Low }}$ cells compared to control cells. O Oligomycin, FCCP Carbonyl cyanide-4-(trifluoromethoxy)-phenylhydrazone, R Rotenone. Results are presented as means \pm s.d.; $n=3$. $\mathbf{d}$ Extracellular acidification rate (ECAR) in $\mathrm{RD}^{\text {Low }}$ cells compared to control cells, as a hallmark of glycolysis. G Glucose, O Oligomycin, 2-DG 2-deoxy-glucose. Results are presented as means \pm s.d.; $n=3$. e Loss of ANT1 appears to have no impact on activation of ERK1/2, S6, and mTORC1 activation, as shown by their phosphorylation levels on western Blots. Tubulin is used as a loading control. $\mathbf{f}$ Decrease in basal level of caspase-3 activity in RD ${ }^{\text {Low }}$ cells. Results are presented as means \pm s.d.; $n=3 .{ }^{*} p<0.05$; two-sided independent samples T-test. $\mathbf{g}$ Decrease in the expression of differentiation markers TNNT3, MYBPC1, and MYOG in RD ${ }^{\text {Low }}$ cells as compared to control cells. Results are presented as means \pm s.d. of three independent $R T-q P C R$. ${ }^{*} p<0.05,{ }^{* * *} p<$ 0.001; two-sided independent samples T-test. $\mathbf{h}$ ANT1 expression in RMS biopsies $(n=147)$ is negatively correlated to two markers of skeletal muscle TNNT3 and MYBPC1. R2 cancer analysis, Davicioni E-TABM-1202 dataset. 

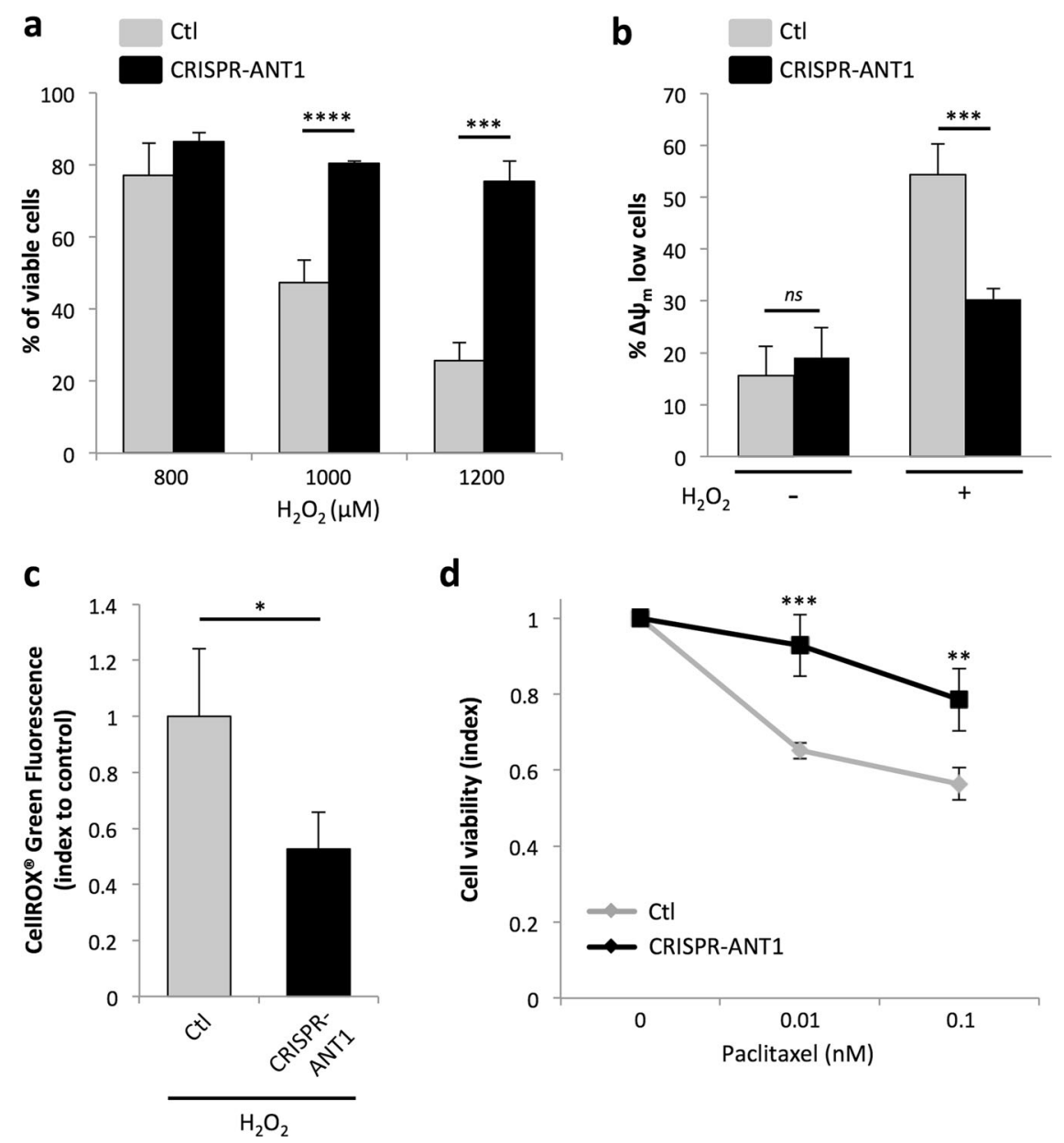

Fig. 3 Low levels of ANT1 favor resistance of tumor cells to death induced by stress and chemotherapies. a Increase in the percentage of viable cells in $\mathrm{RD}^{\mathrm{Low}}$ cells treated upon $\mathrm{H}_{2} \mathrm{O}_{2}$ treatment (image cytometry quantification, DAPI/Acridine orange co-staining). Results are presented as means \pm s.d.; $n=3 .{ }^{* *} p<0.001,{ }^{* * *} p<0.0001$; two-sided independent samples $T$-test. $\mathbf{b}$ Decrease in the cell percentage with loss of mitochondrial membrane depolarization $\left(\Delta \psi_{m}\right)$ in $\mathrm{RD}^{\text {Low }}$ cells upon $\mathrm{H}_{2} \mathrm{O}_{2}$ stress, compared to control cells. Results are presented as means \pm s.d.; $n=3$. ${ }^{* * *} p<0.001$, ns not significant; two-sided independent samples T-test. c ROS production is lower in RD Low cells upon $\mathrm{H}_{2} \mathrm{O}_{2}$ stress. ROS production was evaluated by measuring CellROX fluorescence. Results are presented as means \pm s.d.; $n=3$. ${ }^{*} p<0.05$; two-sided independent samples $T$-test. $\mathbf{d}$ Decreased sensitivity of RD ${ }^{\text {Low }}$ cells to Paclitaxel after $24 \mathrm{~h}$ of treatment, compared to control cells (WST-1 assay). Results are presented as means $\pm s . d$.; $n=3$. ${ }^{* *} p<0.01,{ }^{* * *} p<0.001$; two-sided independent samples $T$-test.

\section{Restoration of ANT1 is sufficient to sensitize RMS cells to} death induced by stress and chemotherapy

As the loss of ANT1 conferred selective advantages to RMS tumor cells, we wondered whether restoration of its expression may have tumor suppressive effects. To this end, we designed Tet-On inducible stable RD and RH30 cell lines to assess the impact of the restoration of ANT1 expression on stress-induced tumor cell death (Fig. $4 \mathrm{a}-\mathrm{f}$ ). The RH30 line was chosen for this rescue experiment, as these cells showed the lowest levels of ANT1 expression. The two induced cell lines will be further designated as $\mathrm{RD}^{\mathrm{High}}$ and $\mathrm{RH} 30^{\mathrm{High}}$. As ANT1 overexpression drives apoptotic cell death ${ }^{40}$, we chose to use a doxycycline dose that was sufficient to restore ANT1 expression without affecting tumor cell death in normal growth conditions
(Fig. 5a). In this steady-state condition, we observed an increase in caspase- 3 activity in $\mathrm{RH} 30^{\text {High }}$ cells, independently of any death stimuli (Fig. 5b). In accordance with the observation that cell viability was not affected by restoring ANT1 expression, we did not detect, in these basal conditions, changes in PARP cleavage, as a downstream effector of the apoptotic pathway (Fig. 5c). We then wondered whether these cells may be more sensitive to stress. Restoring ANT1 expression was indeed sufficient to increase cell sensitivity to $\mathrm{H}_{2} \mathrm{O}_{2}$ treatment in both $\mathrm{RH} 30^{\mathrm{High}}$ and $\mathrm{RD}^{\mathrm{High}}$ lines (Fig. $5 \mathrm{~d}$ and Fig. S2a). Increase in cell death in $\mathrm{RH} 30^{\mathrm{High}}$ cells upon $\mathrm{H}_{2} \mathrm{O}_{2}$ treatment was accompanied by an increase in the percentage of cells with mitochondrial membrane depolarization (Fig. 5e). These results reveal that ANT1 re-expression is sufficient 

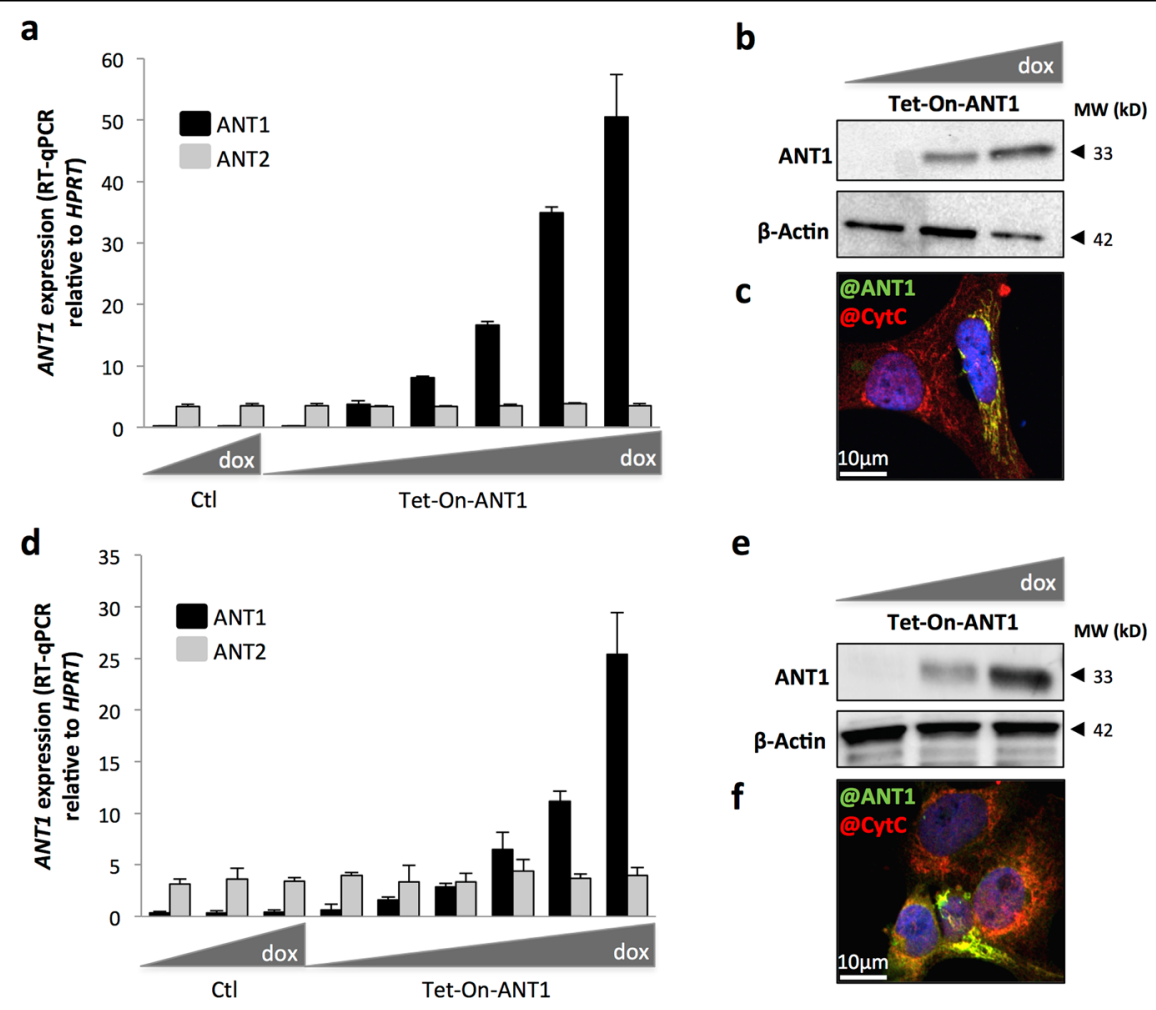

Fig. 4 Efficiency of the inducible Tet-On strategy used to induce ANT1 expression in RMS cells. Efficiency of ANT1 induction by Tet-On system in RH3O (a-c) and RD (d-f) cells, $48 \mathrm{~h}$ after doxycycline treatment, as shown by quantification of ANT1 expression by RT-qPCR, relatively to the housekeeping gene HPRT (a, d), immunoblot with actin as a loading control $(\mathbf{b}, \mathbf{e})$, and immunofluorescence showing colocalization with the cytochrome c mitochondrial marker (c, f).

to restore cell sensitivity to stress-induced death in RMS cell lines.

We then examined whether ANT1 restoration may also counteract the resistance of RMS cells to chemotherapy. Following treatment with Paclitaxel, we observed that viability of $\mathrm{RH} 30^{\mathrm{High}}$ cells was reduced compared to control cells (Fig. $5 \mathrm{f}$ and Fig. S2b). Similar results were obtained with Vincristine (Fig. 5g). To confirm these results in a more relevant system, we set up 3D-spheroid RMS models using both RH30 control and RH30 ${ }^{\text {High }}$ RMS cells. We observed that re-expression of ANT1 in this 3Dsystem was also sufficient to decrease resistance to chemotherapy (Fig. 5h). This effect likely involved induction of apoptosis via MPT since it was associated with an increase in caspase-3 activity (Fig. 5i). Altogether, these results indicate that ANT1 expression may prime cells to death by modulating caspase- 3 activity and may thereby affect their ability to resist stress. Inversely, loss of ANT1 may trigger an increased resistance to stress and to chemotherapies conventionally used for RMS.

\section{Discussion}

Mitochondria are a global hub for intracellular signaling, regulating energy production, metabolism, stress, or apoptotic response to stimuli for example. Previous reports pointed to a pivotal role of ANT1 in some of these processes, especially for the control of OXPHOS metabolism and the induction of MPT-regulated cell death. Here, we unveil that loss of ANT1 expression is sufficient to perturb mitochondria functioning at different levels, thereby supporting oncogenic properties of RMS tumor cells.

Myogenesis involves successive reprogramming of myogenic progenitors, which switch from a dormant to a proliferative state, before differentiating into mature myofibers or entering quiescence (self-renewal). Differentiation requires the acquisition of a metabolism able to sustain the high energetic cost of muscle contraction ${ }^{36,43}$ and is accompanied with an increased resistance to apoptosis. ANT1 expression is suggested to increase upon differentiation, to sustain the switch from a glycolytic metabolism observed in myoblasts to an oxidative one in myofibers ${ }^{11}$. We observed here that ANT1 expression is low in RMS tumors, and is notably reduced compared to fetal muscles, which are frequently used as their nontumoral equivalents ${ }^{44,45}$. Since the precise origin of RMS cells is not clearly defined and may result from the oncogenic transformation of different myogenic 
a

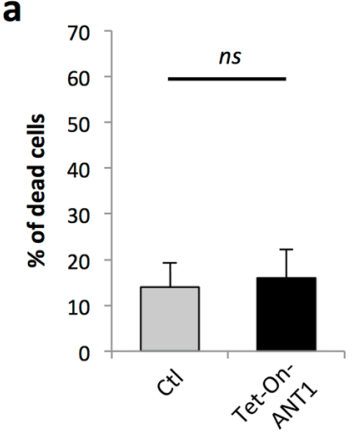

d

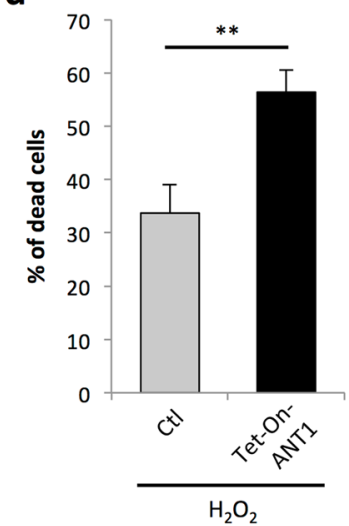

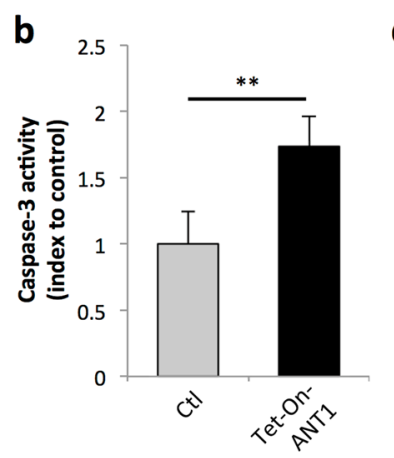

e

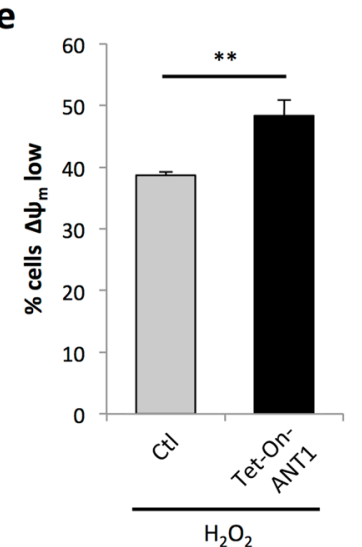

C

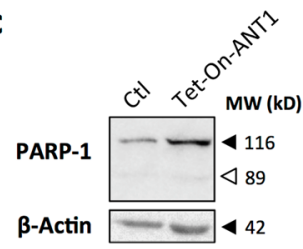

f

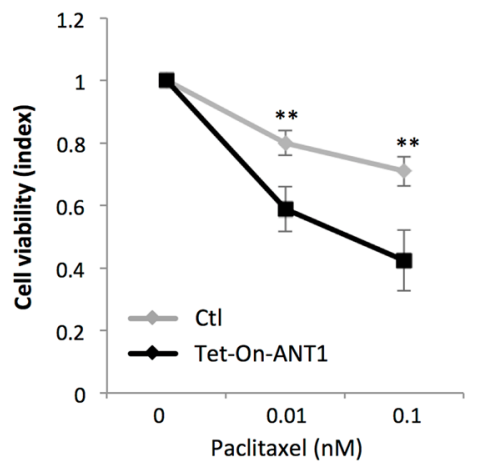

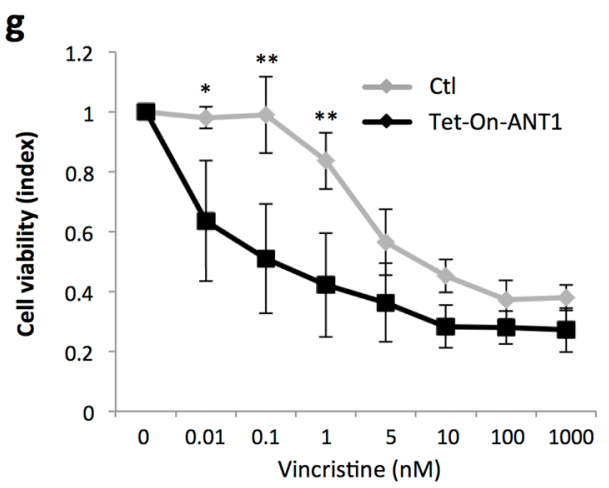

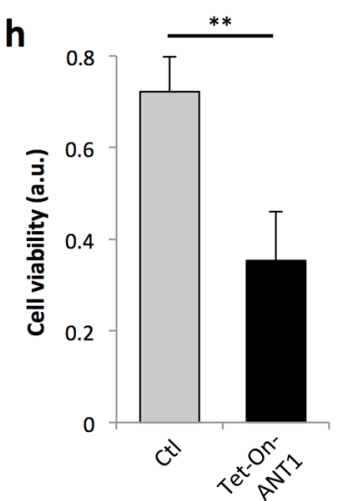

i
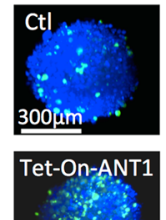

300 m.

Fig. 5 Restoration of ANT1 is sufficient to sensitize RMS cells to death induced by stress and chemotherapy. a Restoring ANT1 expression using an inducible Tet-On system ( $\mathrm{RH} 30^{\text {High }}$ cells) does not change the percentage of dead cells. Dead cells were stained by DAPI and quantified by image cytometry. Results are presented as means \pm s.d.; $n=3$. ns not significant; two-sided independent samples $T$-test. $\mathbf{b}$ Increase in basal caspase-3 activity in $\mathrm{RH} 3 \mathrm{O}^{\text {High }}$ cells. Results are presented as means \pm s.d.; $n=3$. ${ }^{* *} p<0.01$; two-sided independent samples T-test. c Absence of PARP-1 cleavage in $\mathrm{RH} 30^{\text {High }}$ cells in normal growth conditions. Actin is used as a loading control. Increase in the percentage of dead cells (d) and with loss of $\Delta \psi_{\mathrm{m}}(\mathbf{e})$ in $\mathrm{RH} 30^{\mathrm{High}}$ cells upon $\mathrm{H}_{2} \mathrm{O}_{2}$ treatment, compared to control cells. Quantification was made by image cytometry using DAPI and JC-1 staining, respectively. Results are presented as means \pm s.d.; $n=3 .{ }^{* *} p<0.01$; two-sided independent samples T-test. Increased sensitivity of RH30 ${ }^{H i g h}$ cells to $24 \mathrm{~h}$ of Paclitaxel (f) or Vincristine $(\mathbf{g})$ treatment, compared to control cells (WST-1 assay). Results are presented as means \pm s.d.; $n=3 .{ }^{*} p<$ $0.05,{ }^{*} p<0.01$; two-sided independent samples $T$-test. $\mathbf{h}$ Increased sensitivity of RH30 ${ }^{\text {High }} 3 \mathrm{D}$ spheroids to Paclitaxel treatment, compared to control 3D structures (CellTiter-Glo assay). Results are presented as means \pm s.d.; $n=5 .{ }^{* *} p<0.01$; two-sided independent samples $T$-test. i Caspase-3 activity measured by immunofluorescence. Spheroids were imaged by SPIM after active caspase-3 (green) and DAPI (blue) immunostaining. Representative images are shown.

precursors, it is unclear whether the low levels of $A N T 1$ expression correspond to the maintenance of the signature observed in early myogenic precursors or to a secondary loss arising during tumor transformation.
However, our results support the view that increased expression of ANT1 during myogenesis is not only a consequence of muscle cell differentiation but that it may also contribute to this process. In particular, ANT1 may 
influence muscle cell commitment, by modulating caspase-3 steady-state activity, which is a determinant factor during myogenesis ${ }^{39,46-48}$. Perturbing specific metabolic pathways has also been shown to affect myogenic cell fate. We provided here evidence that reduction in ANT1 expression promotes metabolic switch, which may also limit the commitment of RMS cells. Hence, low levels of ANT1 may drive a change of state in RMS cells displaying immature proliferative properties, corresponding somehow to early steps of muscle regeneration, by acting via different processes.

In this study, we established that low expression levels of ANT1 confer selective advantages to RMS tumor cells. Few studies have been dedicated to characterizing the precise role of ANT1 in cancers, due to the high level of homology between ANT1 and ANT2, which precludes their distinction. Moreover, apparently contradictory results have been reported in the two studies published so far on the role of ANT1 in tumorigenesis. Indeed, in these two independent publications, both ANT1 silencing ${ }^{42}$ and its overexpression ${ }^{40}$ led to reduced survival of glioblastoma cells and breast cancer cells, respectively. Our results reconcile these observations by showing that ANT1 acts as a tumor suppressor gene, likely by supporting cell commitment to a differentiation process, via changes in metabolic and death-associated signaling, but especially by priming cells to death and increasing their sensitivity to stressful conditions. However, total loss of ANT1 may have deleterious effects notably by preventing metabolic plasticity of tumor cells and by increasing the oxidative stress level beyond a toxic threshold. Hence, optimal low levels of ANT1 likely exist that strengthen the oncogenic properties of tumor cells. Perturbing this tight equilibrium appears to be an appealing targeted therapeutic strategy in RMS treatment.

\section{Material and methods}

Patients and RNA samples

RMS $(n=67)$ and adult $(n=5)$, fetal $(n=9)$, DMD $(n=5), \mathrm{BD}(n=5)$, and denervated $(n=5)$ muscle biopsies were collected by Centre Léon Bérard and Hospices Civils de Lyon (France) Biological Resources Centres, respectively. Tissue banking and research were conducted according to national ethics guidelines, after obtaining the written informed consent of patients. For mRNA extraction, 10- $\mu \mathrm{m}$-thick FFPE sections were deparaffinized, lysed in $200 \mu \mathrm{L}$ of ATL buffer (Qiagen) with $2 \mu \mathrm{L}$ Proteinase $\mathrm{K}$ (Roche). In total, $1 \mathrm{~mL}$ of Trizol (Life Technologies) was then added to isolate total RNA, before classical purification using $200 \mu \mathrm{L}$ chloroform and $500 \mu \mathrm{L}$ isopropanol with $1 \mu \mathrm{L}$ of Glycoblue (ThermoFisher). After washing in ethanol 75\%, digestion of contaminant genomic DNA was performed for $1 \mathrm{~h}$ at $37^{\circ} \mathrm{C}$ by resuspending the nucleic acid pellets in $15 \mu \mathrm{L}$ of $1 \times$ buffer containing
$0.25 \mu \mathrm{L}$ of $100 \mathrm{mM}$ dithiothreitol (DTT), $2 \mu \mathrm{L}$ of $1 \mathrm{M}$ DNase, and $1 \mu \mathrm{L}$ of RNAsin. A new step of precipitation by isopropanol/ethanol was then performed to eliminate DNase and RNA samples were frozen $\left(-80^{\circ} \mathrm{C}\right)$ until further use.

\section{D and 3D cell cultures and design of cell models}

In vitro studies were conducted using the human $\mathrm{RD}$ ERMS cells (ATCC), and the RH30 ARMS cells (DSMZ). $\mathrm{RD}$ and RH30 cells were routinely maintained under standard conditions $\left(37^{\circ} \mathrm{C}\right.$ and $5 \% \mathrm{CO}_{2}$ in humidified incubator) in Dulbecco's Modified Eagle's Medium (DMEM) supplemented with $10 \%$ fetal bovine serum (FBS) or in Roswell Park Memorial Institute medium supplemented with $10 \%$ FBS, respectively. 3D spheroids were obtained by seeding $2.5 \times 10^{3}$ RH30 cells onto 96well low-attachment plates with $0.5 \%$ Matrigel for 3 days.

For stress induction, cells were exposed to $0-1200 \mu \mathrm{M}$ (RD), 0-75 $\mu \mathrm{M}$ (RH30) of $\mathrm{H}_{2} \mathrm{O}_{2}$ for $6 \mathrm{~h}$ or to Paclitaxel or Vincristine as chemotherapies for $48 \mathrm{~h}$ (see concentrations range in Figures).

To generate stable knockdown cell lines, a conditional CRISPR-Cas9-KRAB system was used. In this system, Cas9 and KRAB from Streptococcus pyogenes are placed under the control of a tetracycline-inducible promoter in pHAGE TRE dCas9-KRAB plasmid, conferring a G418 resistance to cells. Human SLC25A4 (further referred to as ANT1) coding sequence (NM_001151.4, ENST00000281456.11) was cloned at BfuA1 sites in the pLKo.1-puro U6 sgRNA BfuA1 stuffer, conferring puromycin resistance to cells. These plasmids were a gift from Rene Maehr and Scot Wolfe (Addgene plasmids \#50917 and \#50920) ${ }^{49}$. RD and RH30 cell lines were then transduced with both plasmids thanks to lentivirus and using lipofectamine, according to the manufacturer's instructions. Clones were then selected for stable integration for 10 days in G418 (RD: $1 \mathrm{mg} / \mathrm{mL}$; RH30: $600 \mu \mathrm{g} / \mathrm{mL}$ ) and puromycin-containing medium (RD: $0.6 \mu \mathrm{g} / \mathrm{mL}$; RH30: $0.4 \mu \mathrm{g} / \mathrm{mL}$ ). All stable knockdown cells were further tested to check ANT1 expression in response to doxycycline. Control cells were transduced with the pHAGE TRE dCas9-KRAB plasmid alone to exclude any Cas9 off-target effects. All experiments presented in this paper were performed $48 \mathrm{~h}$ after doxycycline induction.

To generate inducible stable cell lines, the human ANT1 coding sequence was cloned at Sal1 and Cla1 sites into the pITR plasmid (gift from Prof. Rolf Marschalek, GoetheUniversity of Frankfurt, Germany), a sleeping beautybased vector allowing the doxycycline-inducible expression of ANT1, using zeocin resistance gene and red fluorescent protein (mCherry) as selection markers. RD and RH30 cell lines were transfected with ANT1-pITR or an empty plasmid as a control, and a sleeping beauty transposase expression vector (SB100X). Clones were 
then selected for stable integration for 10 days in zeocincontaining medium. Control and ANT1-positive clones that stably integrated those constructs were selected by flow cytometry using mCherry as a marker. All stable cells were further tested to check ANT1 expression in response to doxycycline. These cell lines had recently been tested negative for mycoplasma. All experiments presented in this paper were then performed $24 \mathrm{~h}$ after doxycycline induction.

\section{Quantitative RT-PCR}

Total RNA from cell lines was extracted using the Nucleospin RNAII kit (Macherey-Nagel) and $1 \mu \mathrm{g}$ was reverse-transcribed using the iScript cDNA Synthesis kit (BioRad), according to the manufacturer's instructions. Expression of ANT1 [forward primer (5' CAAGGGGATGCTGCCTGACC $\left.3^{\prime}\right)$ and reverse primer $\left(5^{\prime}\right.$ GGACTGCATCATCATTCTACG $3^{\prime}$ )], ANT2 [forward primer (5' CACTGCAAAGGGAATGCTTCCGG 3') and reverse primer $\left(5^{\prime}\right.$ GTACATGATGTCAGTTCCTTT GCG $3^{\prime}$ )], MYOG [forward primer (5' TGCCATCCAGTACATCGAGC $3^{\prime}$ ) and reverse primer (5' GCAGATGATCCCCTGGGTTG $3^{\prime}$ )], TNNT3 [forward primer (5' CCTGGCCAAGGCTGACCAG $3^{\prime}$ ) and reverse primer $\left(5^{\prime}\right.$ CCTTGGCCTTGTCCCTCAG $\left.\left.3^{\prime}\right)\right]$, and MYBPC1 [forward primer (5' GGCACAGTCGGGTG TACAC $\left.3^{\prime}\right)$ and reverse primer (5' CCCAGTAGATTCGTGCACTTC $3^{\prime}$ )] were assessed by real-time quantitative RT-qPCR on a LightCycler ${ }^{\circledR} 480$ instrument (Roche) using the LightCycler ${ }^{\circledR} 480$ SYBR Green I Master Mix, according to the manufacturer's instructions (Roche). The ubiquitously expressed HPRT1 [forward primer (5' TGACACTGGCAAAACAATGCA $\left.3^{\prime}\right)$ and reverse primer (5' GGTCCTTTTCACCAGCAAGCT $\left.3^{\prime}\right)$ ] was used as an internal calibrator.

\section{Cell viability, proliferation, and death assays}

For image cytometry, cells were seeded onto six-well plates at a density of $1 \times 10^{5}$ cells/well and treated with doxycycline to modulate ANT1 expression. Cell number and viability were quantified by image cytometry on a NucleoCounter NC-3000 (Chemometec, Allerød, Denmark) according to the procedure provided by the manufacturer, using a co-staining of Acridine Orange (to quantify total number of cells) and DAPI.

For WST-1, cells were seeded onto 96-well plates at 8000 cells/well. After 24, 48, and $72 \mathrm{~h}$ doxycycline induction, assays were performed using Cell Proliferation Reagent WST-1 (Cat No.11644807001; Roche), according to the manufacturer's instructions. Thereafter, the number of viable metabolically cells was quantified based on the absorbance of formazan formed at $450 \mathrm{~nm}$, analyzed using a microplate reader (Tecan Infinite ${ }^{\circledR}$ M1000 PRO).
For 3D spheroids, cell viability was measured by using the CellTiter-Glo ${ }^{\circledR}$ Luminescent Cell Viability Assay (Promega, Madison, Wisconsin), according to the manufacturer's instructions. This assay is based on the quantification of the ATP produced, reflecting the presence of metabolically active cells. Luminescence was then measured using a microplate reader (Tecan Infinite ${ }^{\circledR}$ M1000 PRO).

Mitochondrial potential measurements were carried out thanks to the fluorescent-based Mitochondrial Potential Assay (Chemometec) according to the following procedure. Cells were seeded onto six-well plates at a density of $1 \times 10^{5}$ cells/well. After $24 \mathrm{~h}$, they were treated with doxycycline, and eventually with $\mathrm{H}_{2} \mathrm{O}_{2}$ or chemotherapy after induction of CRISPR-Cas9/Tet-On systems. Cells were then collected and washed with $1 \mathrm{~mL}$ PBS $1 \times$. Each sample was resuspended in $12.5 \mu \mathrm{L}$ of JC-1 solution (Solution 7, Chemometec). The JC-1 lipophilic cationic dye has dual-fluorescent properties, differentiating healthy and cells in which MPT-regulated cell death is induced. In healthy cells, the intact mitochondrial membrane potential facilitates the accumulation of JC- 1 in the mitochondria, becoming red fluorescent. On the contrary, in cells in which MPT-regulated cell death is engaged, the mitochondrial potential collapses and JC-1 localizes to the cytosol in its monomeric green fluorescent form. After incubation at $37^{\circ} \mathrm{C}$ for $10 \mathrm{~min}$, stained cells were centrifuged at $400 \times g$ for $5 \mathrm{~min}$ at room temperature (RT) and the supernatant was then completely removed without disturbing the cell pellet. Cell pellet was rinsed twice in $1 \mathrm{~mL}$ PBS $1 \times$ and then resuspended in $0.25 \mathrm{~mL}$ of DAPI solution (Solution 8, Chemometec). Each population of cells stained with these different dyes was then quantified by image cytometry using the NucleoCounter NC-3000 (Chemometec).

Caspase-3 activity assay was performed using the Caspase-3 Fluorimetric Assay Kit (Biovision K105-400), according to the manufacturer's instructions. Briefly, $2 \times$ $10^{5}$ cells were seeded onto six-well plates and treated with doxycycline for $24 \mathrm{~h}$ (inducible stable cell lines) or $48 \mathrm{~h}$ (stable knockdown cell lines). Cells were then collected and resuspended in $55 \mu \mathrm{L}$ of cell lysis buffer and incubated on ice for $30 \mathrm{~min}$. After centrifugation, $50 \mu \mathrm{L}$ of sample were loaded into a 96-well plate and mixed with $50 \mu \mathrm{L}$ of reaction buffer. Fluorescence generated by caspase related activity was quantified by fluorescent detection of free AFC after cleavage from the peptide substrate DEVD-AFC using a microplate reader (Tecan Infinite ${ }^{\circledR}$ M1000 PRO). A Bradford protein assay was performed to normalize caspase activity against the total protein amount of the sample.

For 3D cultures, active caspase-3 was defined by immunostaining using Cleaved Caspase-3 (9661S, cell signaling) specific antibody. Briefly, spheroids were 
collected, fixed, permeabilized (4\% paraformaldehyde, PBS $1 \times /$ Triton $0.1 \%$ ) and blocked in PBS BSA $3 \%$ for 45 min. Primary antibody was added (diluted 1/200 in PBS $1 \times$ ) overnight at $4{ }^{\circ} \mathrm{C}$. Secondary antibody was added (diluted $1 / 500$ in PBS $1 \times$ ) for $1 \mathrm{~h}$ with DAPI at RT.

\section{Western blot and co-immunofluorescence}

Cells were lysed in $200 \mu \mathrm{L}$ of $2 \times$ Laemmli Sample Buffer (BioRad, Hercules, California) containing 100 mM DTT. Protein extracts were then analyzed by immunoblot. Briefly, proteins were loaded into $10 \%$ SDS-polyacrylamide gels and blotted onto PVDF sheets (BioRad) using the TurboBlot technology (BioRad). Membranes were blocked with $5 \%$ non-fat dried milk or $5 \%$ BSA in TBS/0.1\% Tween 20 (TBS-T) for $1 \mathrm{~h}$ and then incubated overnight with anti-ANT1/2 (sc-9299, Santa Cruz), antiP-ERK1/2 (4370, Cell signaling), anti-ERK1/2 (9102, Cell signaling), anti-P-mTOR (2971, Cell signaling), antimTOR (2972, Cell signaling), anti-P-S6 (2211, Cell signaling), anti-S6 (2217, Cell signaling), anti-PARP-1 (9542, Cell signaling), anti- $\alpha$-tubulin (ab15246, Abcam), or anti$\beta$-actin (mAB1501R, Sigma). After three washes with TBS-Tween $0.1 \%$, filters were incubated with the appropriate HRP-conjugated secondary antibody (1:10 000, Jackson ImmunoResearch) for $1 \mathrm{~h}$. Detection was performed using the ECL Chemiluminescence System (Pierce). Membranes were imaged on the ChemiDoc Touch Imaging System (BioRad).

Expression of ANT1 and cytochrome c was assessed by co-immunofluorescence on cells fixed $20 \mathrm{~min}$ in $4 \%$ paraformaldehyde and permeabilized in PBS $1 \times /$ Triton $0.2 \%$, using specific antibodies (respectively sc-9299, Santa Cruz, 1:500; and ab90529, Abcam, 1:500). Fluorescence labeling was obtained using corresponding secondary antibodies coupled to Alexa Fluor-488 or Alexa Fluor-647 at a dilution of 1:500 (Invitrogen).

\section{Metabolic analyses}

NMR-based metabolomic analyses were carried out on intact cells using the HRMAS (High Resolution Magic Angle Spinning-Nuclear Magnetic Resonance) method (IRMaGe facility, CEA-Grenoble). After washing $1 \times 10^{6}$ cells with D2O (Deuterium Oxide, Cortecnet), cell pellet was inserted into disposable inserts (Cortecnet), as described previously ${ }^{50}$. Inserts were sealed and frozen into liquid nitrogen and stored at $-80^{\circ} \mathrm{C}$ until further analyses. All ${ }^{1} \mathrm{H}$ HRMAS MR spectra were acquired on a Bruker Avance III spectrometer (IRMaGe, CEA, Grenoble, France) at $500 \mathrm{MHz}^{50}$. Samples were spun at $4000 \mathrm{~Hz}$ and temperature maintained at $4{ }^{\circ} \mathrm{C}$ for all experiments. One-dimensional spectra were acquired using a Carr-Purcell-Meiboom-Gill pulse sequence ( $\mathrm{TE}=30 \mathrm{~ms}, 256$ averages, $17 \mathrm{~min}$ ). The residual water signal was pre-saturated during $1.7 \mathrm{~s}$ of relaxation. Obtained spectra were all processed for multivariate statistics using NMRProcFlow 1.2 online (https://nmrprocflow.org/).

Simultaneous multiparametric metabolic analyses of live cells was performed in the Seahorse XF24 ${ }^{\circledR}$ extracellular flux analyzer (Seahorse Bioscience, USA). RH30 and RD cells were seeded in XF24 V7 multi-well plates $\left(1.5 \times 10^{4}\right.$ cells per well) for $5 \mathrm{~h}$ at $37^{\circ} \mathrm{C}$ in $5 \% \mathrm{CO}_{2}$. One hour before recording the glycolytic activity, cell culture medium was replaced with minimal DMEM $(0 \mathrm{mM}$ glucose) without phenol red supplementation with $143 \mathrm{mM}$ $\mathrm{NaCl}, 2 \mathrm{mM}$ glutamine, and $1 \mathrm{mM}$ sodium pyruvate, $\mathrm{pH}$ 7.4. ECAR was measured under these basal conditions and after sequential injections of glucose $(10 \mathrm{mM})$, the ATP synthase inhibitor oligomycin $(1 \mu \mathrm{M})$, and the glycolysis inhibitor 2-deoxyglucose (100 $\mathrm{mM})$. To record the mitochondrial activity, the same assay medium was used and supplemented with $1 \mathrm{mM}$ sodium pyruvate and $10 \mathrm{mM}$ glucose. OCR was analyzed before and after sequential injections of oligomycin $(1 \mu \mathrm{M})$, the electron transport chain uncoupler FCCP $(1 \mu \mathrm{M})$, and specific inhibitors of the mitochondrial respiratory chain antimycin $\mathrm{A} /$ rotenone $(0.5 \mu \mathrm{M})$. To normalize OCR and ECAR data against cell number, cells were fixed with glutaraldehyde $1 \%$, stained with crystal violet $0.1 \%$ in methanol $20 \%$ (SigmaAldrich), which was finally solubilized in DMSO to measure dye absorption at $600 \mathrm{~nm}$ on a microplate reader (Tecan Infinite ${ }^{\circledR}$ M1000 PRO). SRC was calculated as the difference between maximal respiration and basal respiration as follows: [(OCR after FCCP injection $)-$ (OCR before oligomycin injection)] $\times 100$.

\section{Detection of ROS using CellROX staining}

CellROX $^{\circledR}$ green oxidative stress reagent (Invitrogen, C10444), which is non-fluorescent while in a reduced state and exhibits a strong fluorogenic signal upon oxidation, was used to detect ROS. A total of $5 \times 10^{3}$ cells were seeded onto 96-well plates and treated with $1000 \mu \mathrm{M}$ $\mathrm{H}_{2} \mathrm{O}_{2}$ after $48 \mathrm{~h}$ doxycycline induction. CellROX ${ }^{\circledR}$ green was then added in each well at a final concentration of $500 \mathrm{ng} / \mathrm{mL}$ and incubated for $15 \mathrm{~min}$. Fluorescence intensity was then monitored with an Incucyte $\mathrm{ZOOM}^{\circledR}$ system (Essen BioScience, Michigan, USA). Phase images were obtained every $2 \mathrm{~h}$ for $24 \mathrm{~h}$.

\section{Statistical analysis}

Prism 7.0 (GraphPad) was used for statistics. All data are representative of at least three independent repeats if not otherwise stated. The letter $n$ refers to the number of independently performed experiments representative of the data shown in the figures. The statistical significance in this study was determined by two-sided independent samples $T$-test, with Welch's correction in cases the variances of the populations are not equal. A $p$ value $p<0.05$ was considered to be significant. Statistical significance 
was described as follows: ${ }^{*} p<0.05,{ }^{* * *} p<0.01,{ }^{* * * *} p<0.001$, $* * * * 0<0.0001$. The error bars represent the standard deviation (s.d.).

\section{Acknowledgements}

This work was supported by several charities (Comité de La Ligue contre le Cancer de l'Ain, L'Etoile de Martin, Imagin For Margo, Eva pour la Vie, le Sourire de Lucie, Constance la Petite Guerrière Astronaute, Association Cassandra, InfoSarcomes) and notably by the Fédération Enfants Cancers Santé and the Société Française de lutte contre les Cancers et Leucémies de l'Enfant et de I'Adolescent that we wish to warmly thank. JV benefited from a CIFRE contract from Roche. We thank B. Manship for critical reading of the paper and I. Rochet for help in gathering patients samples.

\section{Author details}

${ }^{1}$ Cell death and Childhood Cancers Laboratory-Equipe labellisée LabEx DEV2CAN, Centre de Recherche en Cancérologie de Lyon, INSERM U1052CNRS UMR5286, Université de Lyon, Centre Léon Bérard, 69008 Lyon, France. ${ }^{2}$ Aix-Marseille Université, Inserm UMR_S 911, Centre de Recherche en Oncologie biologique et Oncopharmacologie, Faculté de pharmacie, Marseille, France. ${ }^{3}$ Department of Cell Physiology and Metabolism, University of Geneva, CMU, CH-1211 Geneva, Switzerland. ${ }^{4}$ Service de BiostatistiqueBioinformatique, Pôle Santé Publique, Hospices Civils de Lyon, F-69003 Lyon, France. ${ }^{5}$ Netris Pharma, Lyon, France. ${ }^{6}$ Université Grenoble Alpes, INSERM US17, MRI facility IRMaGe, 38000 Grenoble, France. ${ }^{7}$ Roche Institute, BoulogneBillancourt, France. ${ }^{8}$ Hospices Civils de Lyon, Lyon, France. ${ }^{9}$ INMG CNRS UMR 5310, INSERM U1217, Université Claude Bernard Lyon, Lyon, France

\section{Conflict of interest}

The authors declare that they have no conflict of interest.

\section{Publisher's note}

Springer Nature remains neutral with regard to jurisdictional claims in published maps and institutional affiliations.

The online version of this article (https://doi.org/10.1038/s41420-020-00302-1) contains supplementary material, which is available to authorized users.

Received: 29 April 2020 Revised: 17 June 2020 Accepted: 6 July 2020 Published online: 24 July 2020

\section{References}

1. Marshall, G. M. et al. The prenatal origins of cancer. Nat. Rev. Cancer 14, 277-289 (2014).

2. Filbin, M. \& Monje, M. Developmental origins and emerging therapeutic opportunities for childhood cancer. Nat. Med. 25, 367-376 (2019).

3. Schwartz, L. M., Gao, Z., Brown, C., Parelkar, S. S. \& Glenn, H. Cell death in myoblasts and muscles. Methods Mol. Biol. 559, 313-332 (2009).

4. Brown, J. M. \& Attardi, L. D. The role of apoptosis in cancer development and treatment response. Nat. Rev. Cancer 5, 231-237 (2005).

5. Fulda, S. Cell death pathways as therapeutic targets in rhabdomyosarcoma. Sarcoma 2012, 326210 (2012).

6. Saab, R., Spunt, S. L. \& Skapek, S. X. Myogenesis and rhabdomyosarcoma the Jekyll and Hyde of skeletal muscle. Curr. Top. Dev. Biol. 94, 197-234 (2011).

7. Heinicke, U., Haydn, T., Kehr, S., Vogler, M. \& Fulda, S. BCL-2 selective inhibitor ABT-199 primes rhabdomyosarcoma cells to histone deacetylase inhibitorinduced apoptosis. Oncogene 37, 5325-5339 (2018).

8. Chamberlain, J. S., Metzger, J., Reyes, M., Townsend, D. \& Faulkner, J. A. Dystrophin-deficient $\mathrm{mdx}$ mice display a reduced life span and are susceptible to spontaneous rhabdomyosarcoma. FASEB J. 21, 2195-2204 (2007).

9. Fanzani, A., Monti, E., Donato, R. \& Sorci, G. Muscular dystrophies share pathogenetic mechanisms with muscle sarcomas. Trends Mol. Med. 19 546-554 (2013)

10. Fernandez, K., Serinagaoglu, Y., Hammond, S., Martin, L. T. \& Martin, P. T. Mice lacking dystrophin or alpha sarcoglycan spontaneously develop embryonal rhabdomyosarcoma with cancer-associated p53 mutations and alternatively spliced or mutant Mdm2 transcripts. Am. J. Pathol. 176, 416-434 (2010).

11. Stepien, G., Torroni, A., Chung, A. B., Hodge, J. A. \& Wallace, D. C. Differential expression of adenine nucleotide translocator isoforms in mammalian tissues and during muscle cell differentiation. J. Biol. Chem. 267, 14592-14597 (1992).

12. Bauer, M. K. Schubert, A., Rocks, O. \& Grimm, S. Adenine nucleotide translocase-1, a component of the permeability transition pore, can dominantly induce apoptosis. J. Cell Biol. 147, 1493-1502 (1999).

13. Halestrap, A. P. Mitochondrial permeability: dual role for the ADP/ATP translocator? Nature 430, 1 (2004).

14. Kaukonen, J. et al. Role of adenine nucleotide translocator 1 in mtDNA maintenance. Science 289, 782-785 (2000).

15. Brenner, C., Subramaniam, K., Pertuiset, C. \& Pervaiz, S. Adenine nucleotide translocase family: four isoforms for apoptosis modulation in cancer. Oncogene 30, 883-895 (2011).

16. Halestrap, A. P. \& Brenner, C. The adenine nucleotide translocase: a central component of the mitochondrial permeability transition pore and key player in cell death. Curr. Med. Chem. 10, 1507-1525 (2003)

17. Vyssokikh, M. Y. \& Brdiczka, D. The function of complexes between the outer mitochondrial membrane pore (VDAC) and the adenine nucleotide translocase in regulation of energy metabolism and apoptosis. Acta Biochim. Polonica 50, 389-404 (2003).

18. Kokoszka, J. E. et al. The ADP/ATP translocator is not essential for the mitochondrial permeability transition pore. Nature 427, 461-465 (2004).

19. Galluzzi, L. et al. Molecular mechanisms of cell death: recommendations of the Nomenclature Committee on Cell Death 2018. Cell Death Differ. 25, 486-541 (2018).

20. Karch, J. et al. Inhibition of mitochondrial permeability transition by deletion of the ANT family and CypD. Sci. Adv. 5, eaaw4597 (2019).

21. Bonora, M. et al. Molecular mechanisms of cell death: central implication of ATP synthase in mitochondrial permeability transition. Oncogene 34, 1608 (2015).

22. Izzo, V., Bravo-San Pedro, J. M., Sica, V., Kroemer, G. \& Galluzzi, L. Mitochondrial permeability transition: new findings and persisting uncertainties. Trends Cell Biol. 26, 655-667 (2016).

23. Kinnally, K. W., Peixoto, P. M., Ryu, S. Y. \& Dejean, L. M. Is mPTP the gatekeeper for necrosis, apoptosis, or both? Biochim. Biophys. Acta 1813, 616-622 (2011)

24. King, M. S. et al. Expanding the phenotype of de novo SLC25A4-linked mitochondrial disease to include mild myopathy. Neurol. Genet. 4, e256 (2018).

25. Korver-Keularts, I. M. et al. Two novel mutations in the SLC25A4 gene in a patient with mitochondrial myopathy. JIMD Rep. 22, 39-45 (2015).

26. Tosserams, A. et al. Two new cases of mitochondrial myopathy with exercise intolerance, hyperlactatemia and cardiomyopathy, caused by recessive SLC25A4 mutations. Mitochondrion 39, 26-29 (2018).

27. Echaniz-Laguna, A. et al. Complete loss of expression of the ANT1 gene causing cardiomyopathy and myopathy. J. Med. Genet. 49, 146-150 (2012).

28. Chevrollier, A., Loiseau, D., Reynier, P. \& Stepien, G. Adenine nucleotide translocase 2 is a key mitochondrial protein in cancer metabolism. Biochim. Biophys. Acta 1807, 562-567 (2011).

29. Sharaf e dein, O., Mayola, E., Chopineau, J. \& Brenner, C. The adenine nucleotide translocase 2, a mitochondrial target for anticancer biotherapy. Curr. Drug Targets 12, 894-901 (2011).

30. Shi, N., Xie, W. B. \& Chen, S. Y. Cell division cycle 7 is a novel regulator of transforming growth factor-beta-induced smooth muscle cell differentiation. J. Biol. Chem. 287, 6860-6867 (2012).

31. Winter, J. et al. Adenine nucleotide translocase 1 overexpression protects cardiomyocytes against hypoxia via increased ERK1/2 and AKT activation. Cell. Signal. 28, 152-159 (2016).

32. Lieu, E. L., Nguyen, T., Rhyne, S. \& Kim, J. Amino acids in cancer. Exp. Mol. Med. 52, 15-30 (2020).

33. Jain, M. et al. Metabolite profiling identifies a key role for glycine in rapid cancer cell proliferation. Science 336, 1040-1044 (2012).

34. Fortini, $P$. et al. The fine tuning of metabolism, autophagy and differentiation during in vitro myogenesis. Cell Death Dis. 7, e2168 (2016).

35. Sonkar, K et al. Focus on the glycerophosphocholine pathway in choline phospholipid metabolism of cancer. NMR Biomed. 32, e4112 (2019).

36. Pala, F. et al. Distinct metabolic states govern skeletal muscle stem cell fates during prenatal and postnatal myogenesis. J. Cell Sci. 131, https://doi.org/ 10.1242/jcs.212977 (2018). 
37. Baechler, B. L., Bloemberg, D. \& Quadrilatero, J. Mitophagy regulates mitochondrial network signaling, oxidative stress, and apoptosis during myoblast differentiation. Autophagy 15, 1606-1619 (2019).

38. McMillan, E. M. \& Quadrilatero, J. Autophagy is required and protects against apoptosis during myoblast differentiation. Biochem. J. 462, 267-277 (2014).

39. Fernando, P., Kelly, J. F., Balazsi, K., Slack, R. S. \& Megeney, L. A. Caspase 3 activity is required for skeletal muscle differentiation. Proc. Natl Acad. Sci. USA 99, 11025-11030 (2002).

40. Jang, J. Y., Choi, Y., Jeon, Y. K., Aung, K. C. \& Kim, C. W. Over-expression of adenine nucleotide translocase 1 (ANT1) induces apoptosis and tumor regression in vivo. BMC Cancer $\mathbf{8}, 160$ (2008).

41. Zamora, M., Merono, C., Vinas, O. \& Mampel, T. Recruitment of NF-kappaB into mitochondria is involved in adenine nucleotide translocase 1 (ANT1)-induced apoptosis. J. Biol. Chem. 279, 38415-38423 (2004)

42. Lena, $\mathrm{A}$. et al. The silencing of adenine nucleotide translocase isoform 1 induces oxidative stress and programmed cell death in ADF human glioblastoma cells. FEBS J. 277, 2853-2867 (2010).

43. Chen, F. et al. YY1 regulates skeletal muscle regeneration through controlling metabolic reprogramming of satellite cells. EMBO J. 38, https:/doi.org/ 10.15252/embj.201899727 (2019).
44. Schaaf, G. J. et al. Full transcriptome analysis of rhabdomyosarcoma, normal, and fetal skeletal muscle: statistical comparison of multiple SAGE libraries. FASEB J. Off. Publ. Fed. Am. Soc. Exp. Biol. 19, 404-406 (2005).

45. Tonin, P. N., Scrable, H., Shimada, H. \& Cavenee, W. K. Muscle-specific gene expression in rhabdomyosarcomas and stages of human fetal skeletal muscle development. Cancer Res. 51, 5100-5106 (1991).

46. Bloemberg, D. \& Quadrilatero, J. Mitochondrial pro-apoptotic indices do not precede the transient caspase activation associated with myogenesis. Biochim Biophys. Acta 1843, 2926-2936 (2014).

47. Ikeda, T. et al. Expression of caspase family and muscle- and apoptosis-specific genes during skeletal myogenesis in mouse embryo. J. Vet. Med. Sci. 71 1161-1168 (2009).

48. Liu, J. et al. Caspase-3-mediated cyclic stretch-induced myoblast apoptosis via a Fas/FasL-independent signaling pathway during myogenesis. J. Cell. Biochem. 107, 834-844 (2009).

49. Kearns, N. A. et al. Cas9 effector-mediated regulation of transcription and differentiation in human pluripotent stem cells. Development 141, 219-223 (2014).

50. Lo Presti, C., Fauvelle, F., Mondet, J. \& Mossuz, P. The differential activation of metabolic pathways in leukemic cells depending on their genotype and micro-environmental stress. Metabolomics Off. J. Metabolomic Soc. 16, 13 (2020). 